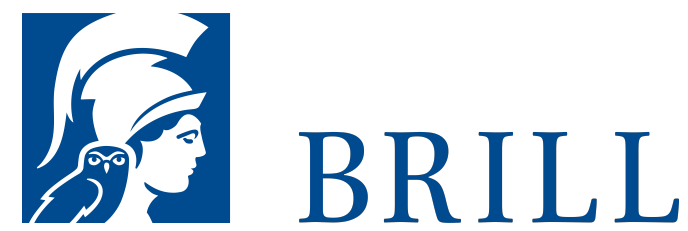

\title{
Erklärungen von Handlungen und Hirnen
}

\section{Author: Florian Leiß}

Stellen die Fortschritte der Neurowissenschaften eine Herausforderung für unser Selbstbild dar? Zunächst einmal ermöglichen uns neurowissenschaftliche Erkenntnisse immer bessere Erklärungen der Vorgänge in menschlichen Gehirnen. Sie sagen etwas über Nervenzellen, Aktionspotentiale und Ionenkanäle. Für unser Selbstbild sind aber andere Erklärungen wesentlicher: die Handlungserklärungen, mit denen wir einander im Alltag unsere Handlungen verständlich machen. Die beiden Arten von Erklärungen sind recht unterschiedlich, weil wir sehr verschiedene Anliegen haben, wenn wir uns mit Nervenzellen oder aber mit Verantwortung auseinandersetzen. Gleichzeitig wissen wir, dass die Vorgänge in unseren Gehirnen irgendetwas mit den Handlungen zu tun haben, für die wir uns verantwortlich fühlen. Wir sollten daher erwarten, dass auch neurowissenschaftliche Erklärungen der Vorgänge in menschlichen Gehirnen in irgendeiner Verbindung mit unseren Handlungserklärungen stehen. Überlegungen zu Unterschieden und Gemeinsamkeiten zwischen neurowissenschaftlichen Erklärungen und Handlungserklärungen können zu einem besseren Verständnis der Zusammenhänge zwischen beiden beitragen. Letztlich gerät unser Selbstbild dadurch nicht in Gefahr - auch wenn einige Konsequenzen für unsere alltäglichen Handlungserklärungen zu erwarten sind. Dafür ergeben sich interessante Impulse für die Handlungstheorie.

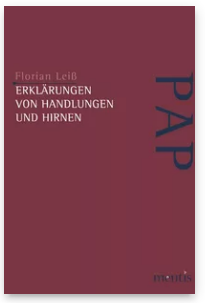

Pages: 227

Seiten

Language:

German

Subjects:

General,

Philosophy

Publisher: Brill | mentis

Series:

Perspektiven der Analytischen

Philosophie

E-Book (PDF)

Released online:

o1 Jan 2013

ISBN: 978-3-

95743-978-9

List price

Paperback

Publication date:

o1 Jan 2013

ISBN: 978-3-

89785-225-9

List price 
For more information see brill.com

Order information: Order online at brill.com +44330 333 0049 | customerservices@brill.com Submission information: brill.com/authors

Titles published by Brill | Fink, Brill | mentis or Brill | Schöningh: +49(o)715413279216| brill@brocom.de 